\title{
Development on the Auto Showering System Concerning Bed Type for the Elderly: Focusing on Nozzle Optimization
}

\author{
Jaesoo Hong, Jonghyun Kim, Keyoungjin Chun \\ Gerontechnology Center, Korea Institute of Industrial Technology, Cheonan, 331-825
}

\begin{abstract}
Objective: The aim of this study is to design an auto showering system regarding bed type for old people or bedridden patients. Background: The rapid growth concerning the aging population leads to an increase in elderly bedridden patients living in senior care centers and hospitals where care givers have difficulty bathing older people with limited mobility. Method: In this study, a showering equipment for experiment was based on anthropometric and researching existing products. The nozzle position was optimized by showering tests and simulations using showering equipment. Results: The problems regarding the existing products were analyzed and the nozzle position was optimized through showering tests. The number, position, and spraying angle of the nozzle were optimized through showering simulations. The automatic showering system concerning bed type was designed by considering their results. Conclusion: When designing an automatic showering system, the most important design element involves determining the position of nozzle and angle of water injection and the number of nozzles. The system was developed by applying the results through user centered-research. Application: The user centered-research for developing products was applied directly in order to develop automatic baths, showering products etc. Furthermore, it was also available to be applied towards senior friendly products.
\end{abstract}

Keywords: Nozzle optimization, Auto showering system concerning bed type, Ergonomics design, Assistive product

\section{Introduction}

한국은 급격한 고령화로 2018년 고령사회(고령자 인구비 율 $14 \%$ 이상) 로 진입할 예정이다(Statistics Korea, 2011). 이러한 고령화 추세로 인하여 노인요양시설 및 노인전문병 원에서 생활하는 병약한 고령자 또한 증가하고 있는 추세이 다(Ministry of Health \& Welfare, 2011). 이와 같은 노인 요양시설이나 노인전문병원에서 몸이 불편한 고령자를 씻기 는 행위인 샤워 및 목욕 수발은 수발자(요양보호사, 케어매 니저 등)에게는 매우 힘든 노동이 되고 있다(R. Hepherd, 2011) (Penn ND et al., 2006). 이러한 샤워 및 목욕 수발자 의 불편함을 해소하고자 국외에서는 여러 기업들에 의해 고
령자나 몸이 불편한 사람들의 샤워 및 목욕 수발을 위한 여 러 종류의 자동샤워장치와 목욕장치가 개발되어 있는 실정 이다(Kim et al., 2011). 그러나 국내 입욕기기 관련업체의 자동 샤워링 및 목욕시스템의 상품개발이나 생산은 미흡한 상황으로 국내시설에서 사용 중인 대부분의 자동입욕기기 는 일본, 유럽 등에서 수입되고 있는 상황이다(Chun et al., 2010).

국내의 입욕기기와 관련된 연구개발 사례를 살펴보면 차 량에 설치된 이동형 목욕시스템이 개발된 사례가 있고, 좌식 형 자동 샤워시스템이 선행연구단계에서 개발한 사례가 있 다(Chun et al., 2011). 그러나 와상 고령자 및 장애인을 위한 와상형 자동 샤워시스템의 개발은 전무한 실정이다.

또한 노인병원이나 요양원(노인전문요양시설: 효원, 구립

Corresponding Author: Keyoungjin Chun. Gerontechnology Center, Korea Institute of Industrial Technology, Cheonan, 331-825.

Mobile: +82-10-3171-6345, E-mail: chun@kitech.re.kr

Copyright@2012 by Ergonomics Society of Korea(pISSN:1229-1684 eISSN:2093-8462). All right reserved.

(c) This is an open-access article distributed under the terms of the Creative Commons Attribution Non-Commercial License(http://creativecommons.org/licenses/by-nc/3.0/), which permits unrestricted non-commercial use, distribution, and reproduction in any medium, provided the original work is properly cited. 
영등포 케어센터)의 인터뷰 결과로는 일본의 와상형 자동 샤워시스템을 사용하고 있지만, 이에 대한 만족도는 높지 않 다. 일본의 와상형 자동 샤워시스템을 사용하는 수발자들의 만족도가 낮은 이유는 샤워시스템의 노즐위치가 적절하게 위치되지 않아 사용자의 몸에 물이 닿지 않는 부분이 많고, 물의 세기가 약해 센 수압의 물로 샤워를 즐기는 한국의 사 용자에게는 적합하지 않다는 의견들이었다(Chun et al., 2011). 또한 선행연구자료에서도 혼자 샤워를 수행해야 하 는 고령자를 위한 샤워수발장비의 노즐위치는 고령자의 균 형능력과 자세에 따라서 적합하게 배치되어야 한다고 주장 하고 있다(Gooptu C and Mulley GP, 1994).

본 연구는 몸이 불편하여 침대에서 누워서 생활하는 고령 자나 와상환자의 샤워수발부담을 최소화할 수 있는 고령자 용 와상형 자동 샤워시스템 개발을 위해 노즐위치와 분사각 도의 최적화 연구를 중심으로 연구를 진행하였다.

따라서 본 연구의 목적은 샤워 시 물이 사용자의 몸에 골 고루 분사될 수 있게 하는 노즐위치 및 분사각 최적화를 통 해 고령자용 와상형 자동 샤워시스템을 개발하는 것이다.

\section{Method}

본 연구에서는 샤워 수발을 하는 수발자의 사용 편의성을 제고하기 위한 방편으로 와상형 자동 샤워시스템의 노즐위 치와 분사각를 최적화하는 방법을 고려하였다. 또한 고령자 의 인체치수를 고려하여 제품의 치수를 제안하는 디자인 가 이드라인을 도출하였다. 그리고 노즐위치와 분사각의 최적화 에 앞서 기존 제품과 유사제품들의 형태분석을 통하여 최종 시제품에 대한 컨셉 디자인을 수행하였다(Figure 1).

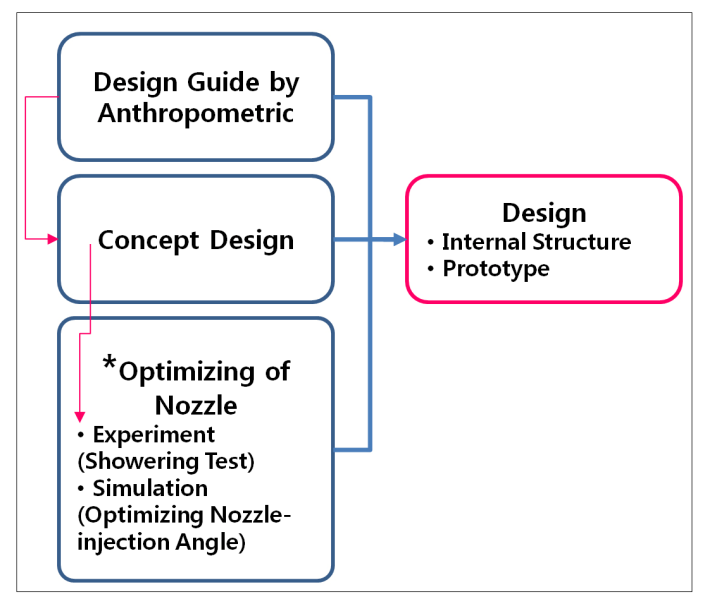

Figure 1. Process of method for showering system design
최적화의 방안은 크게 두 가지 방법으로 나누어진다. 첫 번째로는 노즐 및 스윙노즐의 위치를 최적화할 수 있는 방안 으로 노즐을 가변적으로 위치시킬 수 있는 샤워 실험장치를 활용하여 샤워링 테스트를 실시하였다.

두 번째로는 노즐들의 분사각도와 스윙노즐의 스윙범위를 최적화 하는 방안으로 샤워링 테스트의 노즐위치 최적화 결 과를 반영하여 위치된 노즐들의 분사각도와 스윙노즐의 스 윙범위를 시뮬레이션 하였다.

최종적으로는 최적화된 노즐위치와 분사각도의 결과와 사 용자의 인체치수 분석결과를 시제품의 설계와 외형 디자인 에 반영하여 고령자의 사용성과 안전성을 고려한 내부의 구 조설계 및 외형을 디자인 하였다.

\subsection{Design guideline by anthropometric}

와상형 자동 샤워시스템의 인체측정학적 설계기준은 최종 시제품의 설계가이드라인 작성에 활용할 목적과 샤워링 테 스트를 위한 실험장치의 설계치수 사양을 결정하기 위한 목 적으로 작성하였다.

관련 인체치수에 대한 조사는 Size Korea에서 제공하고 있는 '한국인 정적 인체치수 데이터'를 활용하였다.

와상형 자동 샤워시스템의 설계기준은 고령사용자(65 90세)의 키, 굽힌 팔꿈치 높이, 손바닥 넓이, 엉덩이 너비 등 의 인체치수를 고려하여 설정하였다(Size Korea, 2010).

와상형 자동 샤워시스템의 본체 내부 길이는 키가 큰 사람 이나 작은 사람이나 모두 사용할 수 있게 하기 위해 키가 큰 사람을 기준으로 극단치 설계(최대치 남성 95\%tile) 원 리를 적용하여 설정하였다. 또한 본체 내에 씻는 행위의 수 발 동작이 가능하게 할 수 있는 공간 확보를 위해 여유율 (Redundancy)을 적용하여 설계하였다.

이동용 스트레쳐의 높이 및 샤워 수발 공간의 높이는 굽힌 팔꿈치 높이를 사용하여 수발자가 원하는 높이에서 샤워 수발이 가능할 수 있게 조절식(남성 95\%tile 여성의 5\%tile)으로 설계하였다(Jung et al., 2007).

와상형 자동 샤워시스템의 이동용 스트레쳐 너비는 엉덩 이가 넓은 사람이나 좁은 사람도 불편함이 없도록 엉덩이 가 넓은 사람(여성 $95 \%$ tile)을 기준으로 하여 여유율을 더 해서 결정하였다. 또한 본체 너비는 이동용 스트레쳐의 도킹 공간 및 수발자의 수발 공간(손바닥 너비 최대치, Length between product and body)을 더하여 설계치수를 결정하 였다.

(Table 1) 과 (Table 2)에서와 같이 와상형 자동 샤워시 스템과 관련된 주요 설계 변수(너비, 높이, 길이, 폭 등)에 대한 치수들을 인체치수 분석을 통하여 결정하였다. 그러나 이와 같은 인체치수 분석만으로 결정될 수 없는 와상형 자동 
샤워시스템만의 중요한 설계 변수가 바로 노즐위치와 분사 각도이다. 노즐위치와 분사각도는 와상형 자동 샤워시스템 을 효율적으로 활용하고, 샤워효과를 높일 수 있는 중요한 설계 변수다. 따라서 본 연구에서는 노즐위치와 분사각도의 최적화를 위해서 인체치수 분석을 통해 작성된 가이드라인 을 참고하여 와상형 자동 샤워시스템의 실험장치를 제작하 였고, 와상형 자동 샤워시스템 실험장치를 통한 노즐위치, 개수, 분사각도의 설계 변수를 최적화할 수 있는 샤워링 테 스트와 시뮬레이션을 수행하였다.

Table 1. Anthropometric dimension in the auto showering system concerning bed-type

\begin{tabular}{c|c|c}
\hline Design element & Human factor & $\begin{array}{c}\text { Dimension } \\
\text { (Unit: mm) }\end{array}$ \\
\hline Length of stretcher & Height & 1810 \\
\hline $\begin{array}{c}\text { Length between } \\
\text { product and body }\end{array}$ & Palm width & 94 \\
\hline $\begin{array}{c}\text { Height of } \\
\text { stretcher handle }\end{array}$ & Radial elbow height & 850 \\
\hline $\begin{array}{c}\text { Width of system } \\
\text { and stretcher }\end{array}$ & Hip breadth, sitting & 382.5 \\
\hline
\end{tabular}

Table 2. Criteria of design guideline

\begin{tabular}{c|c|c}
\hline Design element & Human factor & Design criteria \\
\hline $\begin{array}{c}\text { (a): Length of } \\
\text { stretcher }\end{array}$ & Height & $\begin{array}{c}95 \% \text { tile of men }+ \\
\text { Redundancy }\end{array}$ \\
\hline $\begin{array}{c}\text { Length of } \\
\text { showering system }\end{array}$ & Height & (a)+ Redundancy \\
\hline $\begin{array}{c}\text { (b): Width of } \\
\text { stretcher }\end{array}$ & Hip breadth, sitting & $\begin{array}{c}95 \% \text { tile of women }+ \\
\text { Redundancy }\end{array}$ \\
\hline $\begin{array}{c}\text { Width of stretcher } \\
\text { (Mesh bed) }\end{array}$ & $\begin{array}{c}\text { Hip breadth- sitting, } \\
\text { palm width(c) }\end{array}$ & $\begin{array}{c}\text { (b) + (c: } 95 \% \text { tile of } \\
\text { men) + Redundancy }\end{array}$ \\
\hline $\begin{array}{c}\text { Height of } \\
\text { stretcher handle }\end{array}$ & $\begin{array}{c}\text { Radial elbow } \\
\text { height }\end{array}$ & $\begin{array}{c}95 \% \text { tile of men } ~ \\
5 \% \text { tile of women }\end{array}$ \\
\hline
\end{tabular}

\subsection{Concept design}

본 연구의 형태적 디자인 컨셉은 기존의 자동 샤워나 목욕 시스템, Taninig Bed, Sleeping pod의 형태적 분석을 통해 심플하고 유기적인 형태와 파스텔계열의 옐로우나 그린색상 선정, Fiber Reinforced Plastics (FRP)를 통한 제작 이렇게 3 가지 정도가 도출되었다(Fisk and Rogers, 2009).

기능적인 컨셉으로 디자인 요소는 첫 번째로 노즐의 위치 를 최적화 하는 것으로 결정하였다. 두 번째로 외부의 이동 용 스트레쳐의 등받이 틸팅기능, 세 번째로 샤워 시 사용자
가 영상을 감상할 수 있는 LCD모니터 이렇게 3 가지를 주요 기능적 컨셉으로 설정하였다(Figure 2).

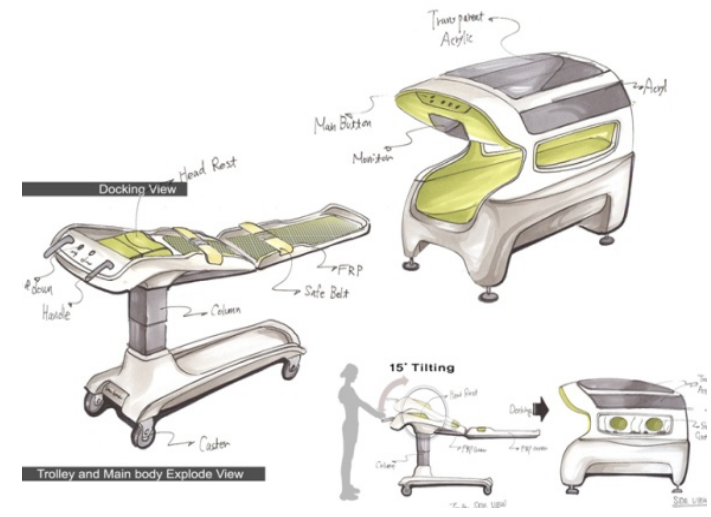

Figure 2. Concept design

\subsection{Method of experiment(Showering Test)}

와상형 자동 샤워시스템의 노즐위치를 최적화하기 위한 방법으로 샤워링 테스트를 실시하였다. 노즐위치 최적화를 위한 방법으로는 첫 번째, 노즐위치를 자유롭게 변화시킬 수 있는 실험장치를 제작하였다. 두 번째, 피실험자의 선정은 고 령자의 신장 최대치를 적용하였다(65 90세, 신장: $174 \mathrm{~cm}$ (남성의 95\%tile)). 세 번째, 현재 일본에서 판매 중인 'O' 사의 경쟁제품을 선정하여 노즐위치를 실측한 결과를 실험 장치에 반영하여 샤워링 테스트를 실시한 후 기존 경쟁제품 의 노즐위치 문제점을 분석하였다. 네 번째로 실험장치에서 기존제품의 노즐위치 문제점을 수정 후 실험하는 과정을 반 복하여 샤워링 테스트를 수행하였다. 노즐위치 최적화 결과 는 샤워링 시뮬레이션에 반영되어 분사각 최적화를 위한 위 치데이터로 활용하였다.

\subsubsection{Equipment of experiment}

(Figure 3)의 샤워링 테스트 장치는 총 24개의 노즐이 구현가능하며 실험장치의 프레임을 프로파일 구조로 제작하 여 노즐의 위치조정 및 분해조립이 용이하게 제작하였다. 따 라서 어떤 노즐이든 원하는 위치에 설치할 수 있어 실측을 통한 기존제품의 노즐위치의 구현, 보완된 노즐의 수정위치 를 구현하는데 적합하게 제작되었다.

\subsubsection{Process of experiment}

경쟁제품의 선정에 있어서는 와상형 자동 샤워시스템의 판매량, 시장점유율, 현재 판매된 실적 등을 고려하여 일본 'O'사의 제품을 선정하였다. 세정 시 노즐위치 문제점을 도 


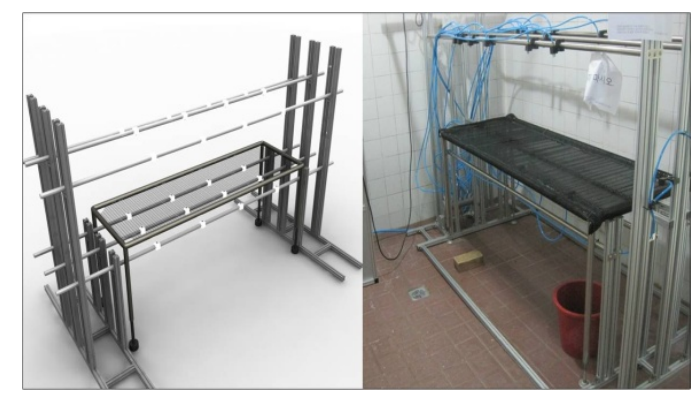

Figure 3. Equipment for experiment(Showering test)



Figure 4. Showering test by body painting

출하고, 기본적인 노즐위치를 설정하기 위해 경쟁제품의 노 즐위치를 실측 후 실험장치에 적용하여 샤워링 테스트를 실 시하였다.

와상형 자동 샤워시스템의 샤워링 테스트에서 피실험자 는 손과 발을 제외한 모든 부위에 바디페인팅을 한 후, 세 제를 사용하지 않고, 노즐에서 분사되는 물로만 세정을 실시 하였다.

세정실험의 결과는 30 초 후, 1 분 후, 2 분 후 사진촬영을 통해 세정되지 않은 부분을 그래픽화 하였고, 세정되지 않은 부분을 보완할 수 있는 수정된 노즐위치를 설정하여 세정실 험을 반복 수행하였다.

또한 위의 실험장치에서는 스윙노즐을 적용하여 적은 노 즐 수로 넓은 범위를 세정할 수 있도록 하였고, 노즐스윙각 도에 대한 실험도 함께 수행하였다.

\subsection{D Modeling of water-injection type}

샤워 시 노즐에서 분사되는 물의 형태를 확인하기 어렵기 때문에 본 연구에서는 노즐의 분사각도 최적화를 위하여 샤 워링 시뮬레이션을 수행하였다.

샤워링 시뮬레이션을 위해서 물의 분사형태를 3 차원 모델 링하였다. 물의 분사형태를 모델링하기 위하여 (Figure 5)에 서와 같이 노즐과 물이 닿는 대상(아크릴 판) 간의 거리별
세정범위를 5 회 반복 측정한 후 평균 값을 적용하여 노즐의 물 분사형태를 모델링 하였다. 수압에 따른 실험상의 오류를 최소화하기 위하여 물탱크 $(70 \ell)$ 와 동일한 수압을 유지할 수 있는 펌프를 사용하였다. 또한 실제 실험장치를 구동한 후 한 개의 노즐을 따로 분리하여 세정범위 측정하는 방법을 통해 실제 샤워장치가 구동되었을 때의 한 개 노즐의 수압과 조건을 동일하게 유지시킨 후 실험을 수행하였다.

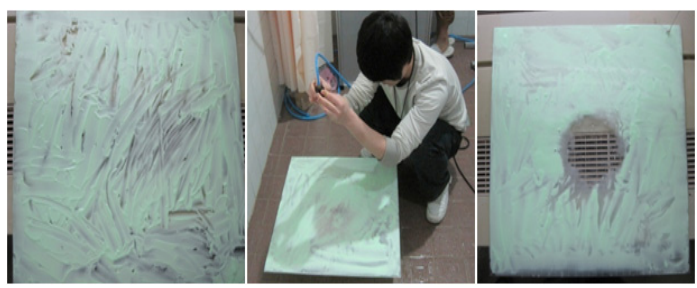

Figure 5. Measuring washing range by distance

거리 별 세정범위를 측정하기 위한 실험에서는 눈금이 있 는 아크릴 판에 풀을 섞은 물감을 칠한 후 $10 \mathrm{~cm}$ 부터 $50 \mathrm{~cm}$ 까지 $10 \mathrm{~cm}$ 씩 5 단계의 실험을 통해 분사거리 별 세정범위를 측정하여 (Figure 6)의 좌측그래프의 실험결과를 토대로 우 측이미지와 같은 물 분사형태를 모델링 하였다.

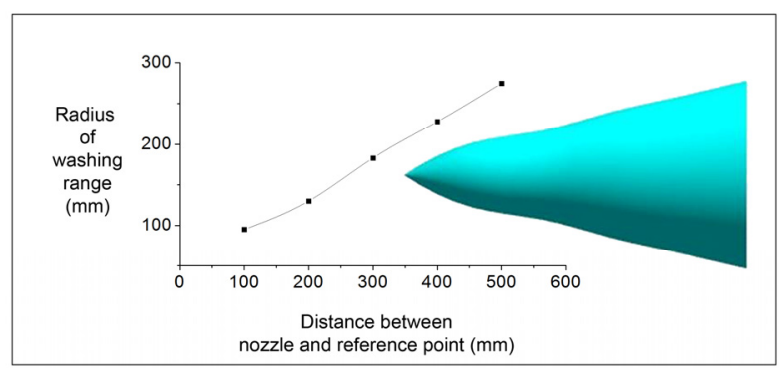

Figure 6. Diameter of washing range by distance(left), 3D modeling of water-injection type(right)

\section{Results}

본 연구의 연구결과는 크게 세 가지로 첫 번째로는 샤워링 테스트를 통한 최적 노즐위치 선정결과, 두 번째로는 샤워링 시뮬레이션을 활용한 스윙노즐의 최적 스윙범위 및 각 노즐 들의 분사각도 최적화 결과, 세 번째로는 노즐위치와 노즐 분사각도를 최적화한 결과를 반영한 최종 Prototype 설계 및 외형 디자인과 최종 시제품 결과 이렇게 3 가지로 나누어 
정리하였다.

\subsection{Result of nozzle position optimization}

일본 경쟁제품의 20 개 노즐위치를 실측한 후 실험장치에 실측한 데이터를 반영하여 노즐들을 위치시킨 후 세정실험 한 결과는 (Figure 7) 과 같이 도출되었다.

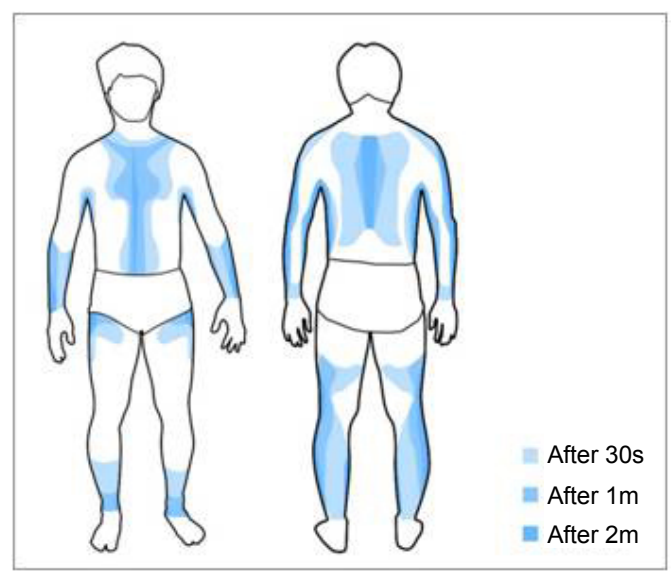

Figure 7. Result of 1 st showering test

1차 샤워링 테스트 후 분석된 문제점은 (1)전면노즐위치 에서 양쪽 노즐 간의 거리가 멀어서, 전면 중심부의 물이 닿 지 않는 부분이 발생하였다. (2)등쪽에 분사되는 아래 부분의 노즐이 중앙 쪽 한 줄로 되어 있고, 중간 Mesh 베드를 통 과해야 하기 때문에, 등쪽 부분에 물이 골고루 분사되지 않 았다. (3)등쪽 부분의 노즐과 대상 간의 거리가 짧아 노즐의 물이 분사되는 면적이 좁았다(Figure 7).

세 가지 문제점에 대한 해결책으로는 (1)전면부에는 대상 과 사이에 Mesh 베드와 같은 장애물이 없지만, 중앙에 노즐 이 없는 단점을 보완하기 위해 중앙에 한 줄로 된 스윙노즐 $\left(30^{\circ}\right)$ 을 배치하였다. (2)등쪽 부분은 대상과 사이에 위치한 Mesh 베드를 극복하고 고른 면적에 분사되게 하기 위하여 대상 간의 거리를 늘리고, 노즐을 두 줄로 배치하였다.

스윙을 적용한 2 차 샤워링 테스트에서는 1 차 세정실험 후 발견된 문제점을 해결하기 위한 노즐배치를 통해 샤워링 테 스트를 진행하였다.

스윙을 적용한 2 차 실험결과에 의하면 2 줄로 노즐을 배치 했던 등 부분의 노즐위치 조정으로 인해 세정되지 않았던 부 분들이 크게 개선되었다. 그리고 목, 어깨에 세정되지 않은 부분들도 스윙을 활용한 노즐분사를 통해 크게 개선된 것을 확인할 수 있었다. 그러나 2차 세정실험에서도 발견된 문제 점으로는 팔이나 뒷부분의 종아리, 허벅지에서 세정되지 않
은 부분이 많이 남아 있음을 발견하였다(Figure 8). 이와 같 은 문제점을 보완하기 위해 뒷부분에 분사되는 노즐의 간격 을 약간 넓히는 대신 노즐 2 개와 발바닥 노즐 2 개를 양쪽 사이드에 배치시키는 안으로 해결책을 제시하였다.

2 차 세정실험에서 발견된 문제점을 보완하기 위해 양쪽에 두 개씩 네 개의 노즐을 보완하였다. 사이드 노즐의 위치와 각도는 시뮬레이션을 통해 적정위치와 분사각도로 결정하여 세정실험을 수행하였다. 이를 통해 (Figure 9) 과 같은 세정 실험 결과를 얻을 수 있었다. 1 차, 2 차 실험결과에서 발견된 문제점을 거의 해결하여 샤워 수발을 제외한 세정만으로도 최적화된 효과를 확인할 수 있었다.

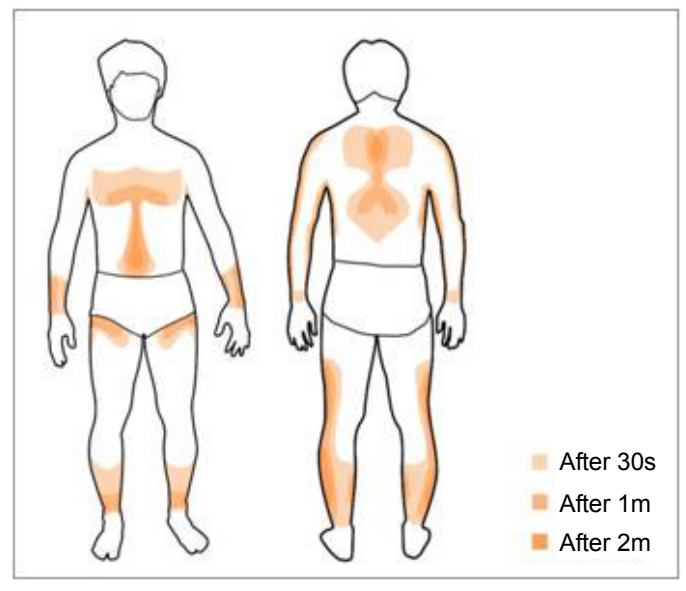

Figure 8. Result of 2nd showering test

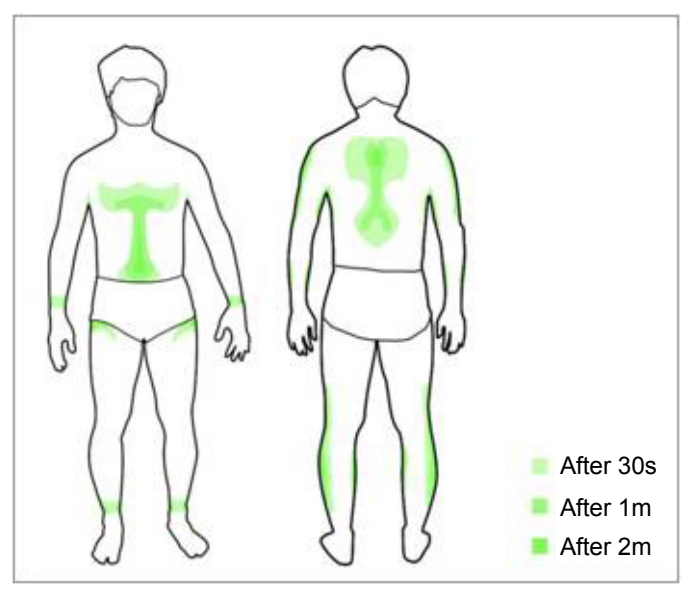

Figure 9. Result of 3rd showering test

최종적으로 노즐의 위치와 수, 간격은 (Table 3)과 같이 개선되었다. 전체노즐의 수는 경쟁제품 $(\mathrm{A})$ 의 노즐위치와 간 격을 최적화(B)하여 19 개에서 20 개로 개선하였다. 세부적 
으로는 몸의 전면부에 물이 분사되는 노즐 수는 13 개에서 스윙노즐 6 개로 개선되었다. 등 부위에 분사되는 노즐의 수 는 4 개에서 10 개로 보완되었고, 발바닥(sole)에 분사되는 노즐 2 개를 제거하고, 허벅지(thigh)에 2개씩 두 줄로 4 개 가 추가되었다. 또한 개선된 노즐의 수와 각 노즐들 사이의 간격은 (Table 3 ) 과 같다.

Table 3. Comparison between nozzle position of competition product(A) and result of optimizing nozzle(B)

\begin{tabular}{|c|c|c|}
\hline $\begin{array}{l}\text { Range of } \\
\text { nozzle- } \\
\text { injection }\end{array}$ & $\begin{array}{l}\text { Number of nozzle } \\
\text { (ea) }\end{array}$ & Interval of nozzle \\
\hline \multirow[t]{2}{*}{$\begin{array}{l}\text { Front of } \\
\text { body }\end{array}$} & $\begin{array}{l}\text { (A): } 13=2 \text { lines } * 6 \\
+ \text { Center } 1\end{array}$ & $\begin{array}{c}(\mathrm{A}): 225 \mathrm{~mm}=\text { line and line } \\
1 \sim 2=65 \mathrm{~mm}, 2 \sim 3=165 \mathrm{~mm} \\
3 \sim 4=210 \mathrm{~mm}, 4 \sim 5=465 \mathrm{~mm} \\
5 \sim 6=210 \mathrm{~mm}\end{array}$ \\
\hline & $\begin{array}{l}\text { (B): } 6=1 \text { line*6 } \\
\text { (Swing nozzles) }\end{array}$ & (B): $1 \sim 2 \sim 3 \sim 4 \sim 5 \sim 6=250 \mathrm{~mm}$ \\
\hline \multirow{2}{*}{$\begin{array}{l}\text { Back of } \\
\text { body }\end{array}$} & (A): $4=1$ line & $\begin{array}{c}\text { (A): } 1 \sim 2=250 \mathrm{~mm} \\
2 \sim 3=295,3 \sim 4=260\end{array}$ \\
\hline & (B): $10=2$ lines $* 5$ & (B): $1 \sim 2 \sim 3 \sim 4 \sim 5=310 \mathrm{~mm}$ \\
\hline \multirow{2}{*}{$\begin{array}{l}\text { Foot } \\
\text { (sole) }\end{array}$} & (A): 2 & (A): $250 \mathrm{~mm}$ \\
\hline & (B): 0 & (B): None \\
\hline \multirow{2}{*}{$\begin{array}{l}\text { Side } \\
\text { (thigh) }\end{array}$} & (A): 0 & (A): None \\
\hline & (B): $4=2$ lines $* 2$ & $\begin{array}{c}\text { (B): } 700 \mathrm{~mm}=\text { line and line } \\
1 \sim 2=450 \mathrm{~mm}\end{array}$ \\
\hline
\end{tabular}

\subsection{Result of nozzle-injection angle optimization}

노즐 분사각을 최적화하는 과정인 샤워링 시뮬레이션은 샤워링 테스트와 연계하여 이루어졌다. (Figure 10)은 1차 샤워링 테스트의 시뮬레이션 결과이다. 시뮬레이션 결과에서 는 상체에 왜 물이 닿지 않는 부분이 발생하고 왜 세정이 잘 되지 않는 곳이 발생하는지 분석할 수 있었고, 스윙노즐 의 동작 시뮬레이션을 통해 베드부를 커버할 수 있는 최소 각도인 $30^{\circ}$ 의 스윙범위를 결정하였다. 2차 샤워링 테스트 후 사이드 노즐을 4 개 추가하여 2 차 시뮬레이션을 수행하였 다. 이러한 분석결과를 샤워링 테스트의 결과와 함께 반영하 여 (Figure 11) 과 같은 최적화된 노즐위치와 노즐 분사각도 를 결정할 수 있었다.

\subsection{Prototype}

본 연구의 결과물인 시제품에 대한 디자인 및 제작은 노즐 위치 최적화와 시뮬레이션 결과를 반영한 내부 구조설계와 외부 케이스의 형태와 색상에 대한 외부 디자인 그리고 시제
품 제작 이렇게 세 가지 측면에서 이루어졌다.

첫 번째로 시제품 내부 디자인은 세정실험과 시뮬레이션 결과를 토대로 구조설계를 진행하였고, 적정 공간에 내부 부 품들의 배치하였다(Figure 12).

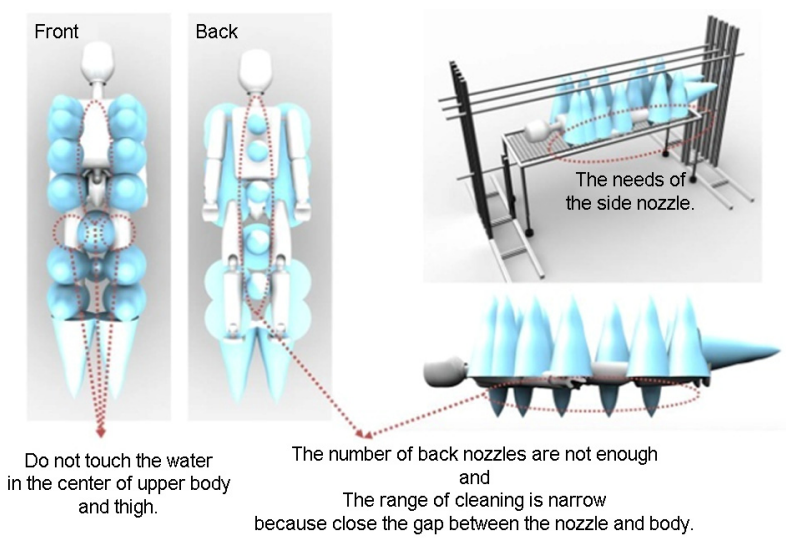

Figure 10. Simulation of competitive product

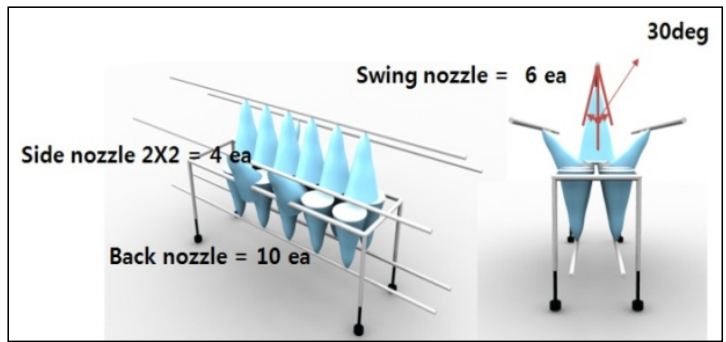

Figure 11. Result of final showering simulation

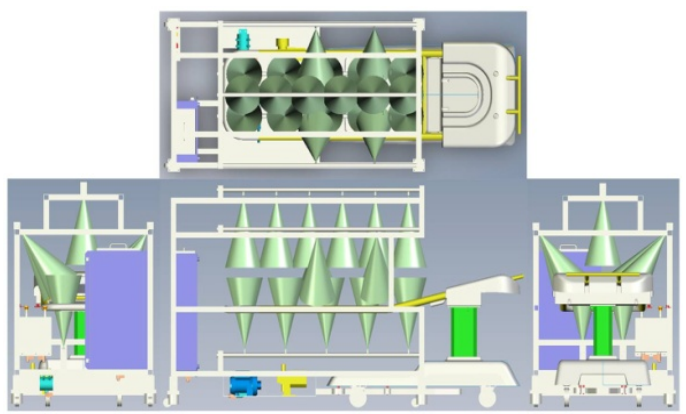

Figure 12. Design of internal structure

두 번째로 외부 디자인은 이동용 스트레쳐의 도킹 안전성 과 컨셉 디자인에서 정의한 디자인방향을 반영하여 심플하 고 유기적인 형태의 파스텔 계열의 색상으로 (Figure 13)과 같이 디자인을 수행하였다(Fisk and Rogers, 2009). 


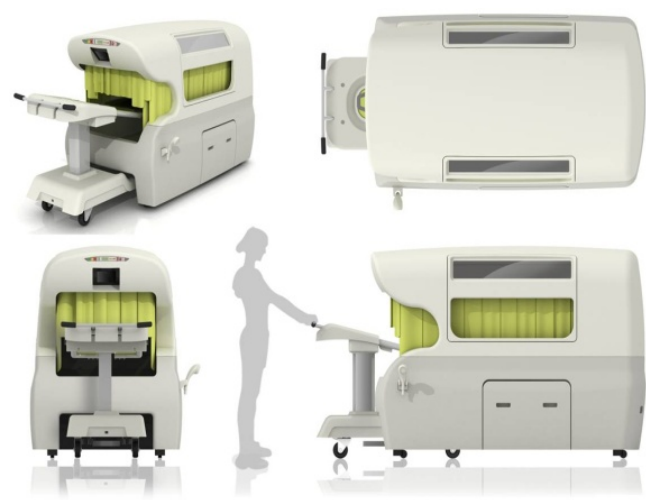

Figure 13. Design of prototype

(Figure 14)의 최종 시제품은 내부 구조프레임 제작과 외부 케이스 제작을 나누어져 제작되어졌다. 내부 구조 프레 임은 구조설계 도면대로 제작되어 부품들을 조립하였고, 외 부 케이스는 목형 제작을 통해 FRP 성형방식으로 제작되어 위와 아래로 2 단계로 분리 · 조립되게 제작함으로써 설치와 해체가 용이하게 제작되었다.

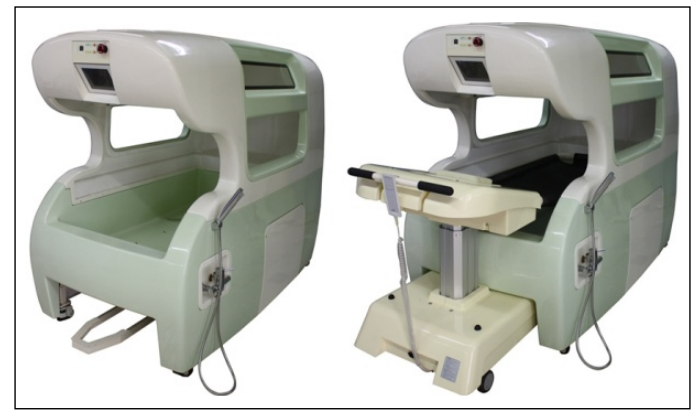

Figure 14. The prototype

\section{Conclusion}

본 연구에서는 노즐위치 최적화를 통하여 누워서 생활하 는 와상환자들의 샤워를 편하게 수발할 수 있는 와상형 자 동 샤워시스템을 개발하였다. 기존의 와상형 자동 샤워시스 템에 대한 연구는 주로 온도조절, 수압조절 등에 초점이 맞 추어졌고, 사용자가 얼마나 효율적으로 샤워를 하고, 수발자
가 편하게 샤워를 수발할 수 있는지에 대한 연구가 미흡하였 다. 또한 제품의 사이즈 역시 사용자(고령자), 수발자 중심 으로 심도 깊게 연구되지 못했다.

따라서 본 연구에서는 인체치수 분석을 통한 제품의 치수 를 결정하였다. 그리고 노즐위치를 최적화를 통해 사용자 몸 에 물이 골고루 분사되게 하여 수발자의 노력을 경감시킬 수 있는 제품 개발에 중점을 두었다.

최적화된 노즐위치는 세정효과를 높일 수 있을 뿐만 아니 라 샤워를 수발하는 수발자, 요양보호사 등의 노동을 줄 일 수 있다. 또한 사용자인 고령자로 하여금 샤워 수발에 따른 수치심을 최소화할 수 있다.

본 연구에서처럼 고령친화제품을 개발할 때 있어 사용자 에게 가장 중요한 설계요소를 도출하고, 설계 변수들을 도출 하였다. 실험한 결과와 도출된 설계 변수들을 반영하는 디자 인방법은 사용자 중심적으로 고령친화제품을 디자인할 수 있는 방법으로 기대된다.

\section{References}

Chun, K. J., et al. Development of An Intelligent Care-free Bathing/ Showering System for Elders, Report of Step 3, Ministry of Knowledge Economy, 2011.

Chun, K. J., Hong, J. H. and Kim, J. H., "A Study on Optimizing the Nozzle Position of Bed style's Showering System", 2010 Spring Conference of Korean Society for Precision Engineering, (pp. 993 -994), 2010.

Fisk, A. D. and Rogers. W. A., Designing for Older Adults (second edition), Taylor \& Francis Group. 2009.

Hepherd, R., Aids for bathing and showering, European Geriatric Medicine 2, 190-193, 2011.

Jung, B. Y. and Lee, D. K., Ergonomics Human Factors, Min Young Sa, 114-128, 2007.

Kim, J. H., Hong, J. H. and Chun, K. J., Case Study on Developing an Elderly Automatic Shower System, Journal of the Ergonomics Society of Korea, 30(5), 629-636, 2011.

Ministry of Health \& Welfare, The number and status of care center for elderly, http://stat.mw.go.kr, 2011.

Penn, N. D., Belfield, P. W., Muscie-Taylor, B.H. and Mulley, G. P., Old and unwashed: bathing problems in the over 70s, BMJ, 298, 1158 $-1159,1989$.

Size Korea, http://sizekorea.kats.go.kr.

Statistics Korea, http://www.kostat.go.kr, 2011 


\section{Author listings}

Jaesoo Hong: jshong94@kitech.re.kr

Highest degree: MS, Department of Mechatronics Engineering, KUT Position title: Senior Researcher, Gerontechnology Center, KITECH Areas of interest: User Analysis, Usability test

Jonghyun Kim: ddalki@kitech.re.kr

Highest degree: MS, Department of Industrial Design Engineering, KUT

Position title: Researcher, Gerontechnology Center, KITECH

Areas of interest: Universal Design, Service Design, User Analysis

\section{Keyoungjin Chun: chun@kitech.re.kr}

Highest degree: Ph. D, Department of Biomechanics, Michigan State Univ.

Position title: Principal Researcher, Gerontechnology Center, KITECH Areas of interest: Development of senior friendly product

Date Received : 2011-12-14

Date Revised : 2012-03-07

Date Accepted : 2012-03-07 